Naohiko Seki • Atsushi Hattori • Akiko Hayashi

Sumie Kozuma $\cdot$ Nobuyuki Miyajima $\cdot$ Toshiyuki Saito

\title{
Cloning, tissue expression, and chromosomal assignment of human MRJ gene for a member of the DNAJ protein family
}

Received: November 16, 1998 / Accepted: January 22, 1999

\begin{abstract}
The DnaJ protein family consists of proteins with a highly conserved amino acid stretch called the " $\mathrm{J}$ - domain". A cDNA clone encoding a new protein with a Jdomain was isolated from a human fetal brain cDNA library. This new member of the DnaJ family of 241 amino acid residues showed $94 \%$ identity with mouse Mrj (accession number, AF035962) and 71\% identity with mouse Msj1 (accession number, U95607) along its entire sequence. Reverse transcription - coupled polymerase chain reaction (RT-PCR) analysis showed the messenger RNA was ubiquitously expressed in various human tissues. The chromosomal location of the gene was determined by PCR-based analyses with both a human/rodent monochromosomal hybrid cell panel and a radiation hybrid panel to map on chromosome $11 \mathrm{q} 25$ region.
\end{abstract}

Key words DnaJ $\cdot$ MRJ $\cdot$ MSJ-1 $\cdot \mathrm{J}$-domain $\cdot$ Chromosome $11 \mathrm{q} 25$

\section{Introduction}

In Escherichia coli (E. Coli ), the heat shock protein DnaJ is known to function together with DnaK and GrpE as a molecular chaperon, that are associated with protein folding, proteolysis, phosphorylation and replication of phage (Caplan et al. 1993, Cyr et al. 1994, Silver and Way 1993).

N. Seki · A. Hattori · A. Hayashi · S. Kozuma · T. Saito $(\bowtie)$ Genome Research Group, National Institute of Radiological Sciences, 4-9-1 Anagawa, Inage-ku, Chiba 263-8555, Japan

Tel. +81-43-206-3135; Fax +81-43-251-9818

e-mail: t_saito@nirs.go.jp

A. Hattori

Biotechnology and Medical Engineering Field, Aisin Cosmos, Tokyo, Japan

N. Miyajima

Laboratory of Genome Information, Kazusa DNA Research

Institute, Chiba, Japan
The DnaJ chaperon was initially identified as a heat shock gene product in E. Coli, an organism in which the DnaJ gene constitutes an operon with the DnaK gene, which encodes the prokaryotic analog of the Hsp70 cognate protein of eukaryotes (Ohki et al. 1986). Several DnaJ homologs have been identified in organisms ranging from yeast to mouse and human (Lindquist and Craig 1988, Cheetham et al. 1992, Berruti et al. 1998). A sequence comparison among these DnaJ-like proteins showed that a typical DnaJ protein is composed of four modules including a highly conserved 70amino acid region at the $\mathrm{N}$-terminal end (J-domain), a glycine-rich region (G-domain) of about 30 residues, a domain containing four Cys-X-X-Cys-X-Gly-X-Gly motifs, and a low similarity region at the C-terminal region of $120-170$ residues (Bork et al. 1992).

To date, at least seven human DnaJ family genes have been identified in public databases (UniGene, http:// www.ncbi.nlm.nih.gov/UniGene/). We searched for other expressed sequence tags (ESTs) showing significant homology to DnaJ family genes against the dbEST database (http:// www.ncbi.nlm.nih.gov/dbEST/) and found several ESTs entries. An array of cDNA fragments covering the entire coding region for a new DnaJ-related protein was obtained.

\section{Isolation of cDNA clone for novel human MRJ protein}

A total of five ESTs (R39700, AA136981, AA223981, AA223975, and AA804461) were selected to design the primer for the 5'-RACE experiment. Their consensus sequence (AGGAAGAATGCACCAACACATTCGCAT) adjacent to the putative poly (A) was used for the primer. Multiple RACE reactions were performed using testis mRNA according the manufacturer's manual (Clontech, Palo Alto, CA, USA). No nested PCR was performed because a single round of RACE reaction gave an apparent signal of amplified products of about $1.6 \mathrm{~kb}$ on an agarose gel. The consensus sequence of the independent RACE products was employed in the definitive structure of MRJ cDNA. The determined nucleotide sequence and deduced 
cetggagctgtgaggagattcgggecgtcaccctgectcccetgcgtcccgccaccggec

CTAGGCGTGCAGAGACATGCCTCACCCGAGGATATTAAAAAGGCATATCGGAAACTGGCA TTCAAATCGATATCAACTTCAACTAAAATGGTTAATGGCAGAAAAATCACTACAAAGAGA

$\begin{array}{llllllllllllllllllll}I & V & E & N & G & Q & E & R & V & E & V & E & E & D & G & Q & L & K & S & L\end{array}$ ACAATAAATGGTAAGGAGCAGCTGCTGCGCTTGGATAACAAGTAAttcaacgcacgcact

$\begin{array}{lllllllllllllll}T & I & N & G & K & E & Q & L & L & R & L & D & N & K & *\end{array}$

taacagaaatgttaaactataacaagcaccatttgaggattaacaggaacatttttttga

900 agatttcaaacgaactcgactttcagtataattgtacctaaagtatttataaacagctca tcggagcctctatttgtcatagacttttgagttgattgttgggaccacataataggacca 1020 ttttttttttgtctttaaaattgttgtaaatctctgtatgcactttgcttttttattaaa 1080 cgtactccaaggtgagtcttgactctttagtgtaggacaagattgtacactaacaccagc 1140 atggacctgcttttcattgtgtctgaaatgtgagccacgtagtgtcggcctgctgtgaag 1200 ttaacattgccaggacgattcttctacagaaataatttcaatttttttcagtatttagta 1260 gtgaaagatattaatacattaatggtaatacatttctggtttaatataaattaaggatgt tttctagttgtgcatgaatgctggcaacttagtaagttttgacaattgtttaaatatgta atgttaagcttaggtttaaaaagtaaagctggtaaactgggtctttgtcatttgcttta aaaaaaaaaaaaagaaataaatgcgaatgtgttggtgcattc

Fig. 1. The human MRJ cDNA sequence and predicted protein. The J-motif is underlined and the putative polyadenylation signal is doubleunderlined. The sequence have been submitted with accession number AB014888. An asterisk denotes the termination codon

amino acid sequence are shown in Fig.1. The cDNA contains a total length of $1485 \mathrm{bp}$, including a $5^{\prime}$-noncoding region of $100 \mathrm{bp}$, an open reading frame of $726 \mathrm{bp}$, and a 3'noncoding region of $659 \mathrm{bp}$. The open reading frame encodes a protein of 241 amino acid residues with a calculated molecular weight of $37 \mathrm{kDa}$. A canonical poly-adenylation signal, AATAAA, was located 21 bp upstream of the poly (A) (Fig.1). The nucleotide sequence data reported here will appear in the DDBJ, EMBL, and GenBank nucleotide sequence databases with the accession number of AB014888. The predicted protein contains a J-motif (residues 46-65) and a canonical J-domain (residues 2-75). Ho- 


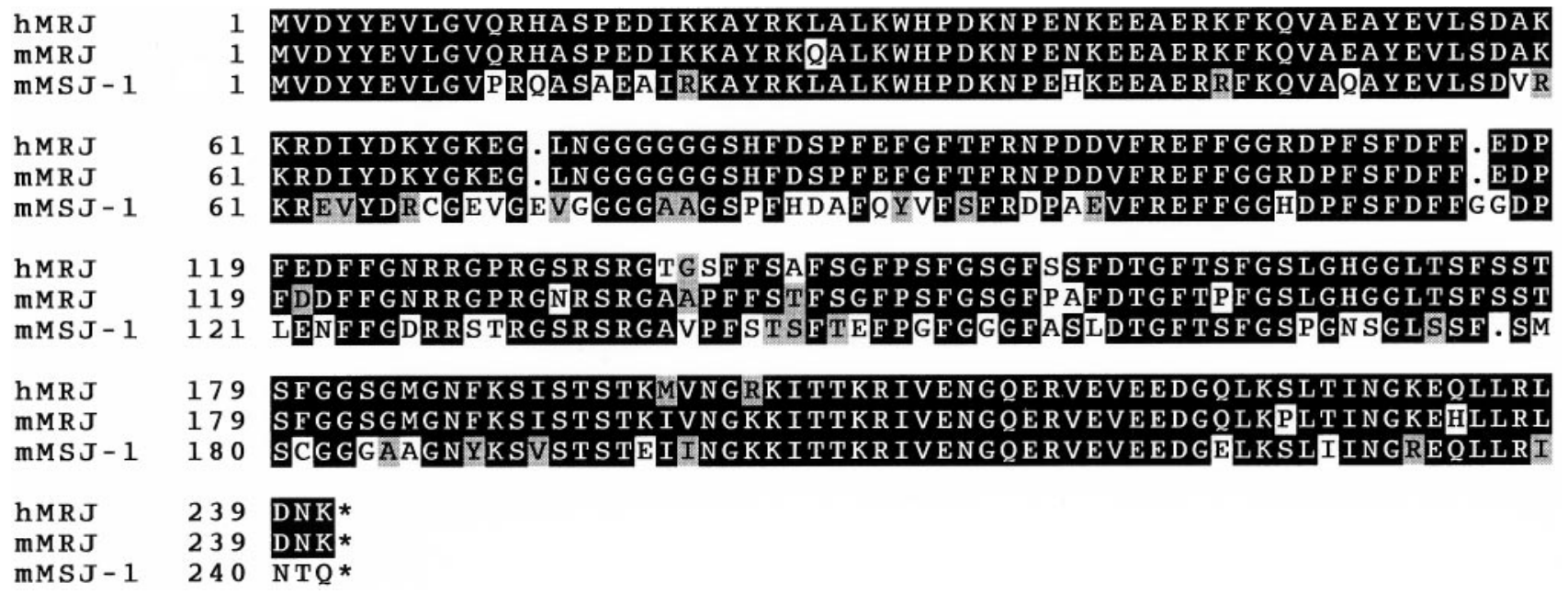

Fig. 2. Alignment of human MRJ (hMRJ; accession number, AB014888), mouse Mrj (mMRJ; accession number, AF035962), and mouse Msj-1 (mMSJ-1; accession number, U95607). Identities are

indicated by black background and similar residues are shadowed. Asterisk denotes the termination codon

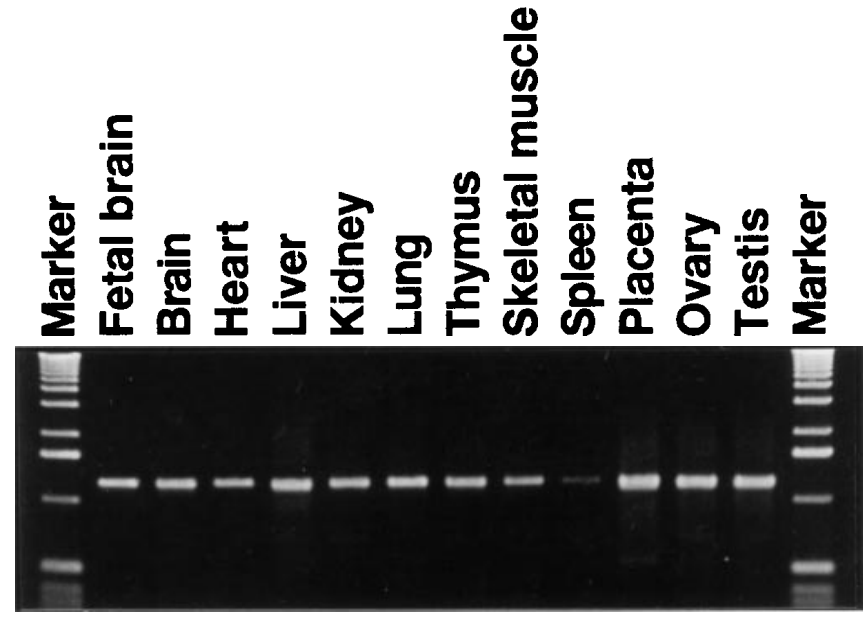

Fig. 3. Tissue distribution analysis of human $M R J$ transcript using reverse transcription-coupled polymerase chain reaction. The 12 tissues examined are indicated above each lane

mology searches indicated that the deduced amino acid sequence shares homology with mouse Mrj (accession number, AF035962, 94\% identity, 96\% similarity) and mouse Msj-1 (accession number, U95607, 71\% identity, $80 \%$ similarity) (Fig.2). From these results, we concluded that the obtained cDNA encodes the human MRJ protein. The protein contains the two structural features of the Jdomain at the amino terminus region and the glycine-rich region distal to the J-domain, but not the cysteine-rich repeats in the middle of the protein. The J-domain is a conserved sequence of about 70 amino acids, thought to be a site of functional interaction between the DnaJ-like protein and the Hsp70 homolog. While the J-domain is present in all DnaJ-like proteins, the other sequence features, the G-domain and cysteine-rich sequence, are less well conserved (Lindquist and Craig 1988).

\section{Tissue expression of the human MRJ gene}

Since the mouse $M r j$ gene has been reported only in the nucleotide databases, no information on its expression profile is available. We examined the distribution of human MRJ transcript in various human tissues by reverse-transcription -coupled chain reaction (RT-PCR) according to a previously described method (Saito et al. 1998, Seki et al. 1998). The primer set used for the RT-PCR covered the whole protein coding region of the messenger (5'CTGGAGCTGTGAGGAGATTC-3' and 5'-CTGTAGAAGAATCGTCCTGGC-3). No amplification was detected from human genomic DNA due to multiple exons (data not shown). A clear common signal of the expected size (1228-bp-long) was detected in all the tissues examined (Fig. 3), indicating that the MRJ gene is ubiquitously transcribed in various tissues and would be involved in the basic housekeeping function of cells. In contrast, a very close relative of $M R J$, mouse Msj-1, is specifically expressed in testicular germ cells (Berruti et al. 1998). It remains to be investigated how these two highly conserved isologs share or alternate their function in cells.

\section{Chromosomal assignment of the human MRJ gene}

Chromosomal assignment of the MRJ gene was done by PCR analysis of a human/rodent somatic cell hybrid panel, and a radiation hybrid panel as described previously (Saito et al. 1997, 1998, Seki et al. 1997, 1998). The specific amplified PCR primers were designed at the $3^{\prime}$-untranslated region of the gene (5'-ACCTGCTTTTCATTGTGTCTG3', 5'-CTGTAGAAGAATCGTCCTGGC-3', the PCR product size was $116 \mathrm{bp}$ ). First, a specific amplified product for human was detected only from the hybrid containing 
Fig. 4. Chromosomal placement of the human $M R J$ gene at a relative distance to framework markers on the WICGR (Whitehead Institute for Biomedical Research/MIT Center for Genome Research) radiation hybrid map of the human genome (http://carbon.wi.mit. edu:8000/cgi-bin/contig/phys_map). The approximate corresponding cytogenetic location of the gene on the long arm of the telomeric region of chromosome 11 is indicated. Distances of the markers are in centirays (cR) and centimorgans $(\mathrm{cM})$ from the top of the chromosome 11 linkage group

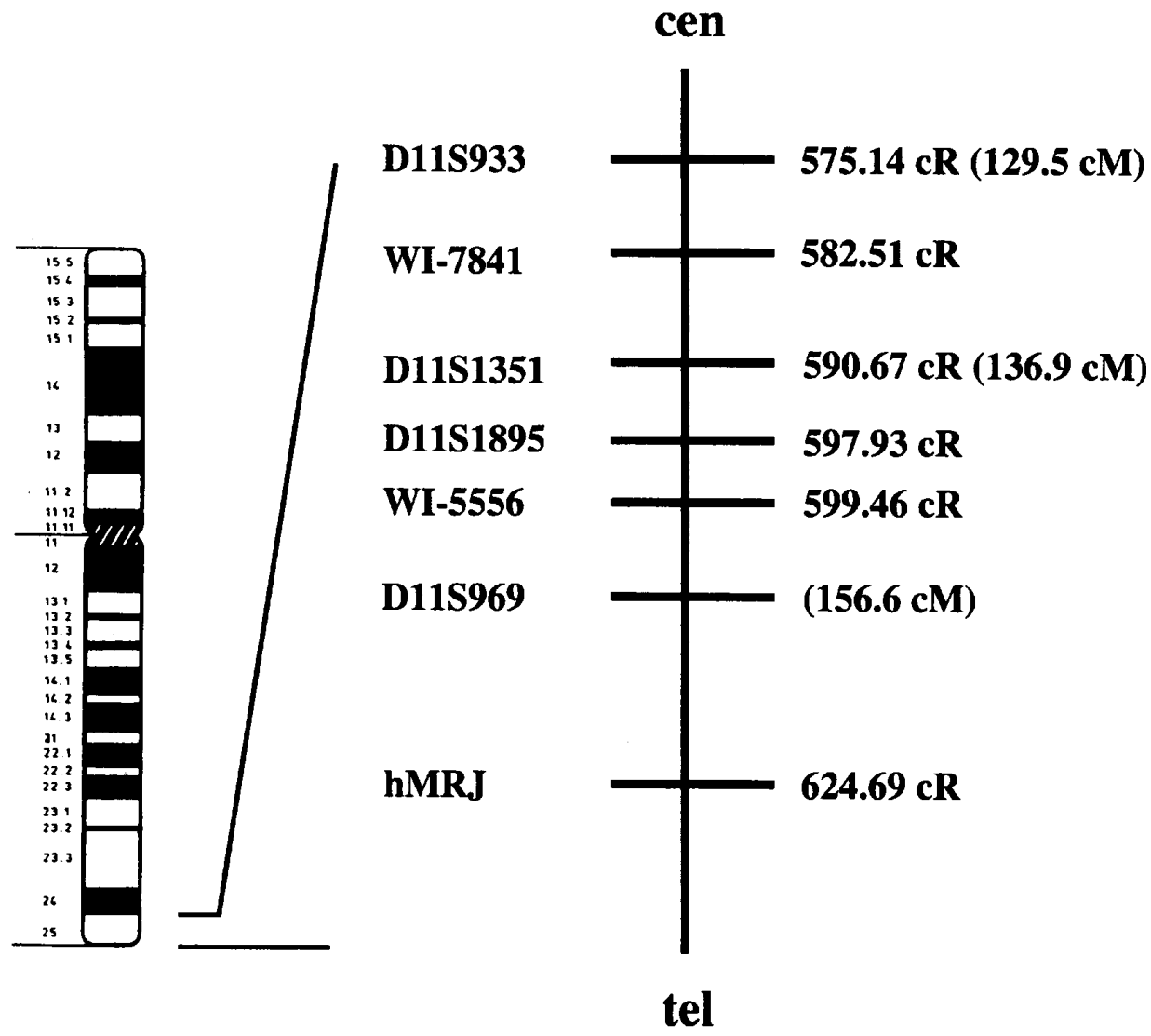

\section{Chromosome 11}

human chromosome 11 (data not shown). Then, we performed further mapping analysis, using a PCR-based radiation hybrid panel (Genebridge 4; Research Genetics, Huntsville, AL, USA) with the same primers as those used in the assay for the human/rodent somatic cell hybrid panel. Statistical analysis of the radiation hybrid data was performed using the RHMAPPER software package (http:// carbon.wi.mit.edu:8000/cgi-bin/contig/rhmapper.pl). The data vector for the human MRJ gene was 1010110110 00001101100100010010000000011101101110011110110010 001011101000010000101101001000101 . Although the telomeric region contains few markers and the linkage framework of the radiation hybrid panel has relatively low resolution, the consequent report indicated that the gene was placed to $25.23 \mathrm{cR}$ distal from WI-5556 (lod $>3.0)$, which was cytogenetically mapped to the $11 \mathrm{q} 25$ region (Fig.4). A significant linkage of the following diseases is found to be assigned to this chromosomal region by referring to Online Mendelian Inheritance in Man (OMIM, http://www. ncbi. nlm. nih.gov/omim) and the Entrez database (http://www.ncbi. nlm.nih.gov/Entrez). A hereditary disease, histiocytosis with joint contractures and sensorineural deafness (Moynihan et al. 1998) was recently mapped to the telomeric region of chromosome 11. Several putative tumor suppressor genes for anal canal carcinoma (Muleris et al. 1987), desmoplastic infantile ganglioglioma (Park et al. 1996), oral cancer (Uzawa et al. 1996), sporadic breast cancer (Koreth et al. 1997), and subcutaneous sacrococcygeal myxopapillary ependymoma, (Sawyer et al. 1998) have also been assigned to this region. The MRJ gene positioned to this chromosomal region could be a useful marker for, and contribute toward, loss of heterozugosity studies and genetic linkage analysis of this genomic locus.

\section{References}

Berruti G, Perego L, Borgonovo B, Martegani E (1998) MSJ-1, a new member of the DNAJ family of proteins, is a male germ cell-specific gene product. Exp Cell Res 239: 430-441

Bork P, Sander C, Valencia A, Bukau B (1992) A module of the DnaJ heat shock proteins found in malaria parasites. Trends Biochem Sci 17: 129

Caplan AJ, Cyr DM, Douglas MG (1993) Eukaryotic homologues of Escherichia coli dnaJ: a diverse protein family that functions with hsp70 stress proteins. Mol Biol Cell 4: 555-563

Cheetham ME, Brion JP, Anderton BH (1992) Human homologues of the bacterial heat-shock protein DnaJ are preferentially expressed in neurons. Biochem J 284: 469-476

Cyr DM, Langer T, Douglas MG (1994) DnaJ-like proteins: molecular chaperones and specific regulators of Hsp70. Trends Biochem Sci 19: $176-181$

Koreth J, Bakkenist CJ, McGee JO (1997) Allelic deletions at chromosome 11q22-q23.1 and 11q25-qterm are frequent in sporadic breast but not colorectal cancers. Oncogene 14: 431-437

Lindquist S, Craig EA (1988) The heat-shock proteins. Annu Rev Genet 22: 631-677

Moynihan LM, Bundey SE, Heath D, Jones EL, McHale DP, Mueller RF, Markham AF, Lench NJ (1998) Autozygosity mapping, to chromosome $11 \mathrm{q} 25$, of a rare autosomal recessive syndrome causing 
histiocytosis, joint contractures, and sensorineural deafness. Am J Hum Genet 62: 1123-1128

Muleris M, Salmon RJ, Girodet J, Zafrani B, Dutrillaux B (1987) Recurrent deletions of chromosomes $11 \mathrm{q}$ and $3 \mathrm{p}$ in anal canal carcinoma. Int J Cancer 39: 595-598

Ohki M, Tamura F, Nishimura S, Uchida H (1986) Nucleotide sequence of the Escherichia coli dnaJ gene and purification of the gene product. J Biol Chem 261: 1778-1781

Park JP, Dossu JR, Rhodes CH (1996) Telomere associations in desmoplastic infantile ganglioglioma. Cancer Genet Cytogenet 92: 4-7

Saito T, Seki N, Ishii H, Ohira M, Hayashi A, Kozuma S, Hor T (1997) Complementary DNA cloning and chromosomal mapping of a novel phosphatidylinositol kinase gene. DNA Res 4 301-305

Saito T, Seki N, Ohira M, Hayashi A, Kozuma S, Hattori A, Hori T (1998) Assignment of the ZIP kinase gene to human chromosome 19 p13.3 by somatic hybrid analysis and fluorescence in situ hybridization. J Hum Genet 43: 209-211
Sawyer JR, Miller JP, Ellison DA (1998) Clonal telomeric fusions and chromosome instability in a subcutaneous sacrococcygeal myxopapillary ependymoma. Cancer Genet Cytogenet 100: 169-175

Seki N, Nimura Y, Ohira M, Saito T, Ichimiya S, Nomura N, Nakagawara A (1997) Identification and chromosome assignment of a human gene encoding a novel phosphatidylinositol-3 kinase. DNA Res 4: 355-358

Seki N, Hayashi A, Abe M, Araki R, Fujimori A, Fukumura R, Kozuma S, Ohira M, Hori T, Saito T (1998) Chromosomal assignment of the gene for human DNA-PKcs interacting protein (KIP) on chromosome $15 \mathrm{q} 25.3-\mathrm{q} 26.1$ by somatic hybrid analysis and fluorescence in situ hybridization. J Hum Genet 43: 275-277

Silver PA, Way JC (1993) Eukaryotic DnaJ homologs and the specificity of HSP70 activity. Cell 74: 5-6

Uzawa K, Suzuki H, Komiya A, Nakanishi H, Ogawara K, Tanzawa H, Sato K (1996) Evidence for two distinct tumor-suppressor gene loci on the long arm of chromosome 11 in human oral cancer. Int $\mathbf{J}$ Cancer 67: 510-514 